\title{
Astroglial PGC-1alpha increases mitochondrial antioxidant capacity and suppresses inflammation: implications for multiple sclerosis
}

Philip G Nijland ${ }^{1,2^{*}+}$, Maarten E Witte $2,4^{*}+$, Bert van het Hof $^{2}$, Susanne van der Pol ${ }^{2}$, Jan Bauer ${ }^{3}$, Hans Lassmann $^{3}$, Paul van der Valk', Helga E de Vries ${ }^{2}$ and Jack van Horssen ${ }^{2}$

\begin{abstract}
Recent evidence suggests that reactive oxygen species (ROS) produced by inflammatory cells drive axonal degeneration in active multiple sclerosis (MS) lesions by inducing mitochondrial dysfunction. Mitochondria are endowed with a variety of antioxidant enzymes, including peroxiredoxin-3 and thioredoxin-2, which are involved in limiting ROS-induced damage. In this study, we explored the distribution and role of the mitochondrial antioxidants peroxiredoxin-3 and thioredoxin-2 as well as their regulator peroxisome proliferator-activated receptor gamma coactivator1-alpha (PGC-1a) in MS pathogenesis.

Immunohistochemical analysis of a large cohort of MS patients revealed a striking upregulation of PGC-1a and downstream mitochondrial antioxidants in active demyelinating MS lesions. Enhanced expression was predominantly observed in reactive astrocytes. To elucidate the functional role of astrocytic PGC-1a in MS pathology, we generated human primary astrocytes that genetically overexpressed PGC-1a. Upon an oxidative insult, these cells were shown to produce less ROS and were found to be more resistant to ROS-induced cell death compared to control cells. Intriguingly, also neuronal cells co-cultured with PGC-1a-overexpressing astrocytes were protected against an exogenous oxidative attack compared to neuronal cells co-cultured with control astrocytes. Finally, enhanced astrocytic PGC-1a levels markedly reduced the production and secretion of the pro-inflammatory mediators interleukin- 6 and chemokine (C-C motif) ligand 2. Our findings suggest that increased astrocytic PGC-1a in active MS lesions might initially function as an endogenous protective mechanism to dampen oxidative damage and inflammation thereby reducing neurodegeneration. Activation of PGC-1a therefore represents a promising therapeutic strategy to improve mitochondrial function and repress inflammation.
\end{abstract}

Keywords: Reactive astrocytes, Neurodegeneration, Prx3, Trx2, ROS

\section{Introduction}

Multiple sclerosis (MS) is the leading cause of nontraumatic neurological disability among young adults in Europe and North-America [1]. MS is generally characterized as an immune-mediated disease in which infiltrating macrophages and T-lymphocytes induce focal demyelination and neurodegeneration by producing large amounts

\footnotetext{
*Correspondence: p.nijland@vumc.nl; Maarten.Witte@med.uni-muenchen.de ${ }^{\dagger}$ Equal contributors

'Department of Pathology, MS Center Amsterdam, VU University Medical Center, Amsterdam, The Netherlands

${ }^{2}$ Department of Molecular Cell Biology and Immunology, Neuroscience Campus Amsterdam, VU University Medical Center, Amsterdam, The Netherlands

Full list of author information is available at the end of the article
}

of inflammatory cytokines and reactive oxygen species (ROS) $[2,3]$. In the process of inflammation-driven demyelination, astrocytes become activated and data is emerging that reactive astrocytes play an important and dual role in various processes underlying MS pathogenesis (for review see $[4,5])$. Reactive astrocytes can aggravate inflammation and blood-brain barrier (BBB) leakage by secreting inflammatory molecules, but also facilitate BBB repair, secrete immunosuppressive molecules and possess neuroprotective properties [6-9]. Importantly, astrocytes are the main source of antioxidants and are thus essential for scavenging ROS in MS lesions [10,11].

Macrophages and activated microglia produce significant amounts of ROS, which leads to increased 
mitochondrial ROS production thereby enhancing local oxidative stress and mitochondrial dysfunction [12]. ROS-mediated mitochondrial dysfunction is an important cause for axonal and neuronal degeneration, which are the pathological substrates of permanent disability in MS patients [13-15]. Mitochondria continuously produce ROS and are therefore equipped with a specific and efficient antioxidant apparatus, which under physiological circumstances efficiently controls the mitochondrial redox balance, thereby ensuring adequate mitochondrial function [16,17]. Peroxiredoxin-3 (Prx3) is the mitochondria-specific member of the peroxiredoxin family and catalyzes the reduction of various peroxides, a reaction in which peroxiredoxins are oxidized [18]. To regain its antioxidant capacity, Prx3 is reduced by mitochondrial thioredoxin-2 ( $\operatorname{Tr} \times 2)$, which by itself is also capable of directly reducing various ROS and oxidized proteins [19]. Proper function of Prx3 and Trx2 are of particular importance in the central nervous system (CNS) as neurons are highly dependent on a healthy mitochondrial population. In fact, different studies have indicated that Prx3 and Trx2 have neuroprotective properties [20,21].

Recently, we showed that the expression of mitochondrial antioxidants is reduced in the cortex of MS patients compared to control grey matter. Notably, the observed decrease strongly correlated with a significant decrease in the levels of transcriptional co-regulator peroxisome proliferator-activated receptor gamma coactivator 1-alpha (PGC-1 $\alpha$ ) [22]. PGC-1 $\alpha$ has multiple binding partners and is thereby able to simultaneously induce transcription of a broad set of genes, most of which are involved in energy metabolism and redox handling, including Prx3 and Trx2 [23,24]. Thus far, data on the expression of PGC- $1 \alpha$ and mitochondrial antioxidant enzymes in various stages of MS white matter lesions is limited. However, oxidative stress and mitochondrial dysfunction are most prominent in white matter lesions and contribute to axonal loss [25]. Therefore, it is imperative to understand and identify potential protective mechanisms aimed at restoring the redox balance and improving mitochondrial function in MS lesions. Hereto, we set out to explore the cellular distribution of key mitochondrial antioxidants and their transcriptional regulator PGC-1 $\alpha$ in a large set of well-characterized MS white matter lesions.

We here describe that the expression of mitochondrial antioxidants and PGC- $1 \alpha$ is markedly increased in inflammatory white matter lesions, particularly in reactive astrocytes. Overexpression of PGC- $1 \alpha$ in human astrocytes reduced astrocytic ROS production and protects astrocytes from exogenous ROS-induced cell death. Moreover, neurons co-cultured with PGC- $1 \alpha$-overexpressing astrocytes are more resistant to exogenous ROS. Interestingly,
PGC- $1 \alpha$ also reduced interleukin- 6 (IL-6) and chemokine (C-C motif) ligand 2 (CCL2) production by human astrocytes under normal and inflammatory conditions. Our data indicate that increased expression of PGC- $1 \alpha$ and downstream mitochondrial antioxidants in astrocytes in MS lesions represents an intrinsic defense mechanism to restore the redox balance, suppress inflammation and promote neuro-axonal survival during an inflammatorydriven oxidative attack.

\section{Material and methods}

\section{Brain tissue}

Formalin-fixed, paraffin-embedded brain sections were obtained from 19 patients and 10 matched non-neurological controls from the Netherlands Brain Bank, Amsterdam and the Medical University Vienna, Austria. Detailed clinical data are summarized in Table 1 . The study was approved by the institutional ethics review board (VU University Medical Center, Amsterdam; Medical University of Vienna EK Nr. 535/2004) and all donors or their next of kin provided written informed consent for brain autopsy, use of material and clinical information for research purposes.

\section{Immunohistochemistry}

Five $\mu \mathrm{m}$-thick paraffin sections were collected on Superfrost Plus glass slides (VWR international; Leuven, Belgium) and dried overnight at $37^{\circ} \mathrm{C}$. Sections were pretreated and stained as described previously [26]. In short, sections were deparaffinized in a series of xylene ( $3 \times 5 \mathrm{~min}$ ), $100 \%$ ethanol, $96 \%$ ethanol, $70 \%$ ethanol and water. Endogenous peroxidase activity was blocked by incubating the sections in methanol with $0.3 \% \mathrm{H}_{2} \mathrm{O}_{2}$. Next sections were incubated with appropriate primary antibodies (see Additional file 1: Table S1) in phosphate buffered saline (PBS) supplemented with 1\% bovine serum albumin (BSA; Roche diagnostics $\mathrm{GmbH}$, Mannheim, Germany) overnight at $4^{\circ} \mathrm{C}$ and stained with the EnVision horseradish peroxidase (DAKO, Glostrup, Denmark) kit followed by 3,3' diaminobenzidine-tetrahydrochloridedihydrate (DAB; DAKO). After a short rinse in tap water, sections were counterstained with haematoxylin for $1 \mathrm{~min}$ and intensely washed with tap water for $5 \mathrm{~min}$.

Fluorescence immunohistochemistry in early active MS lesions was performed on paraffin sections as described previously [27]. For confocal fluorescent double labelling or triple labelling with primary antibodies from different species, antibodies were applied simultaneously at $4^{\circ} \mathrm{C}$ overnight (Additional file 1: Table S1). After washing with Dako washing buffer (DakoCytomation, Glostrup, Denmark), secondary antibodies consisting of donkeyanti-mouse Cy3 (Jackson ImmunoResearch, 1:200), biotinylated donkey-anti-rabbit (Amersham Pharmacia Biotech; 1:200) and Cy5-conjugated donkey-anti-goat, were applied 
Table 1 Clinical data of MS patients and non-neurological controls

\begin{tabular}{|c|c|c|c|c|c|c|}
\hline Case & Age (years) & MS type & Sex & $\begin{array}{l}\text { Post-mortem } \\
\text { delay (h:min) }\end{array}$ & $\begin{array}{l}\text { Disease duration } \\
\text { (years) }\end{array}$ & Lesion stages \\
\hline MS 1 & 73 & ND & $m$ & $6: 45$ & 26 & $\mathrm{ClA}$ \\
\hline MS 2 & 63 & PP & $\mathrm{m}$ & $7: 05$ & 25 & $C A$ \\
\hline MS 3 & 56 & SP & $\mathrm{m}$ & $8: 00$ & 27 & $\mathrm{ClA}$ \\
\hline MS 4 & 66 & ND & $\mathrm{m}$ & $7: 45$ & ND & A \\
\hline MS 5 & 41 & PP & $\mathrm{m}$ & $7: 20$ & 14 & $\mathrm{~A}, \mathrm{CA}$ \\
\hline MS 6 & 49 & SP & $\mathrm{m}$ & $8: 00$ & 25 & $\mathrm{ClA}$ \\
\hline MS 7 & 66 & PP & $\mathrm{m}$ & $7: 30$ & 26 & $2^{*} \mathrm{CA}$ \\
\hline MS 8 & 61 & SP & $\mathrm{m}$ & $9: 15$ & 30 & $3^{*} \mathrm{CA}, \mathrm{CIA}$ \\
\hline MS 9 & 44 & PP & $\mathrm{m}$ & $12: 00$ & 13 & CA \\
\hline MS 10 & 44 & $\mathrm{SP}$ & $\mathrm{m}$ & $10: 15$ & 22 & CA \\
\hline MS 11 & 54 & PP & $\mathrm{m}$ & $8: 15$ & 15 & $3^{*} \mathrm{~A}$ \\
\hline MS 12 & 45 & AMS & $\mathrm{m}$ & ND & 1 week & $3^{*} \mathrm{~A}, \mathrm{CA}, \mathrm{ClA}$ \\
\hline MS 13 & 35 & AMS & $\mathrm{m}$ & ND & 6 weeks & $5^{*} \mathrm{~A}, 2^{*} \mathrm{ClA}$ \\
\hline MS 14 & 40 & RR & $f$ & ND & 10 & A \\
\hline MS 15 & 34 & AMS & f & ND & 0,3 & A \\
\hline MS 16 & 78 & AMS & $\mathrm{m}$ & ND & 0,2 & $\mathrm{~A}, \mathrm{CA}$ \\
\hline MS 17 & 41 & $\mathrm{SP}$ & $\mathrm{m}$ & ND & 10,6 & A \\
\hline MS 18 & 46 & SP & $f$ & ND & 37 & $\mathrm{CA}, \mathrm{Cl} A$ \\
\hline MS 19 & 51 & AMS & $f$ & ND & 0,5 & $\mathrm{~A}, 3^{*} \mathrm{CA}$ \\
\hline Ctrl 1 & 66 & NA & $f$ & $7: 00$ & NA & NA \\
\hline Ctrl 2 & 71 & NA & $\mathrm{m}$ & $8: 55$ & NA & NA \\
\hline Ctrl 3 & 58 & NA & $\mathrm{m}$ & $5: 15$ & NA & NA \\
\hline Ctrl 4 & 62 & NA & $\mathrm{m}$ & $7: 20$ & NA & NA \\
\hline Ctrl 5 & 78 & NA & $\mathrm{m}$ & $17: 40$ & NA & NA \\
\hline Ctrl 6 & 51 & NA & f & $5: 36$ & NA & NA \\
\hline Ctrl 7 & 70 & NA & $\mathrm{m}$ & ND & NA & NA \\
\hline Ctrl 8 & 46 & NA & $\mathrm{m}$ & ND & NA & NA \\
\hline Ctrl 9 & 37 & NA & $\mathrm{m}$ & ND & NA & NA \\
\hline Ctrl 10 & 39 & NA & $f$ & ND & NA & NA \\
\hline
\end{tabular}

$\mathrm{SP}=$ secondary progressive $M S ; \mathrm{PP}=$ primary progressive $M S ; A M S=$ Acute $M S ; N D=$ not determined; $N A=$ non applicable; $m=m a l e ; f=$ female; $A=$ active lesion; $\mathrm{CA}=$ chronic active lesion; $\mathrm{CI} \mathrm{A}=$ chronic inactive lesion.

simultaneously for 1 hour at room temperature, followed by application of streptavidin-Cy2 (Jackson ImmunoResearch; 1:75) for 1 hour at room temperature. Fluorescent preparations were embedded and examined using a confocal laser scan microscope (Leica SP5, Leica Mannheim, Germany) equipped with lasers for 504, 488, 543 and $633 \mathrm{~nm}$ excitation. Scanning for Cy2 $(488 \mathrm{~nm})$, Cy3 and $\mathrm{Cy} 5$ was performed sequentially to rule out fluorescence bleed through.

For colocalization studies in late active lesions, deparaffinized sections were incubated for 30 minutes with $10 \%$ animal serum, of which the source was determined by the specific secondary antibody used followed by incubation with the primary antibodies (Additional file 1: Table S1). Alexa Fluor (Life Technologies, Vienna, Austria) labeled secondary antibodies were used for fluorescent labeling. Images were taken on a Leica DM6000 microscope (Leica Microsystems Heidelberg GmbH, Mannheim, Germany). All primary antibodies were diluted in $0.01 \mathrm{~mol} /$ L phosphate buffered saline (PBS; pH 7.4) containing $1 \%$ BSA and 0,05\% Tween-20 (SigmaAldrich, StLouis, MO, USA), which also served as a negative control.

\section{Cell culture and lentiviral-induced (over)expression}

Primary human cerebellar astrocytes (ScienCell, Carlsbad, CA) were cultured in astrocyte medium (ScienCell). The human neuroblastoma cell line SH-SY5Y and the human astrocytoma cell line U373 were both cultured in DMEM/ F12 (1:1, Life Technologies) containing 10\% foetal calf serum (FCS, Life Technologies), $2 \mathrm{mM}$ L-glutamin (Life 
Technologies), and penicillin/streptomycin $(50 \mathrm{mg} / \mathrm{ml}$; Life Technologies) in $5 \% \mathrm{CO}_{2}$ at $37^{\circ} \mathrm{C}$.

To overexpress Prx3, its coding sequence was amplified from primary human astrocyte cDNA with primers (forward: CGGATCCCGATGGCGGCTGCTGTAGGA reverse: CCGAATTCCTACTGATTTACCTTCTGAAAG) and cloned into the lentiviral vector pRRL-cPPT-CMVX2-PRE-SIN (kindly provided by Dr. J. Seppen, Academic Medical Center, Amsterdam, the Netherlands). The human Trx2 plasmid was kindly provided by Professor Jones (Emory University, Atlanta, GA, USA) and the human PGC-1 $\alpha$ plasmid by Professor Strömstedt (Department of Pharmaceutical Biosciences, University of Oslo, Norway). Both vectors were amplified and cloned into the pRRL lentiviral vector $[28,29]$. Lentiviral vectors were produced by co-transfecting subconfluent human embryonic kidney (HEK) 293 T cells with the Prx3, Trx2 or PGC-1 $\alpha$ expression plasmid and lentiviral packaging plasmids (pMDLg/ pRRE and pRSV-Rev), using calcium phosphate as a transfection reagent. Lentiviral vectors were collected $24 \mathrm{~h}$ after transfection. The supernatant was centrifuged to remove cell debris and stored at $-80^{\circ} \mathrm{C}$. Human astrocytes were transduced with the lentivirus-containing PGC-1 $\alpha$. Human astrocytes overexpressing PGC- $1 \alpha$ are indicated as PGC- $1 \alpha^{+}$astrocytes throughout the manuscript. U373 astrocyte-like cells were also transduced with PGC- $1 \alpha$ and with Prx3 or Trx3 containing lentivirus since primary human astrocytes were scarce. Forty-eight hours after transduction, stable cell lines were selected by puromycin treatment $(2 \mu \mathrm{g} / \mathrm{mL}$; SigmaAldrich). The overexpression efficiency was determined by qPCR and western blotting and stable cell lines were used for functional studies described hereafter. Human astrocytes and U373 cells stably transduced with the empty pRRL vector served as control. Finally, SH-SY5Y neuroblastoma cells and human astrocytes were stably transduced with the SHC003 turboGFP vector (Sigma Aldrich), to generate a green fluorescent cell line.

\section{Real-time quantitative PCR}

Total RNA from astrocyte cultures was isolated using Trizol (Invitrogen, Carlsbad, CA, USA) according to manufacturer's protocol. mRNA concentrations were measured using Nanodrop (Nanodrop Technologies, Wilmington, DE, USA). cDNA was synthesized with the Reverse Transcription System kit (Promega, Madison, WI, USA) following manufacturer's guidelines. Quantitative PCR (qPCR) reactions were performed in an $\mathrm{ABI} 7900 \mathrm{HT}$ sequence detection system using the SYBR Green method (Applied Biosystems, Foster City, CA, USA) as described previously [30]. Obtained mRNA expression levels were normalized to XPNPEP1 (Qiagen, Venlo, the Netherlands) expression levels, which a recent study found to be the housekeeping gene of choice in human CNS studies and was in our hands also the most consistent in human primary astrocytes [31]. All oligonucleotides were synthesized by Ocimum Biosolutions (Ocimum Biosolutions, IJsselstein, the Netherlands) (Additional file 2: Table S2).

\section{Western blot}

Protein isolation from astrocytes was performed using M-PER buffer supplemented with protease and phosphatase inhibitors according to manufacturer's protocol (Thermo Scientific, Rockford, IL, USA). Protein concentrations were measured using BCA protein assay (Thermo Scientific). Western blot was performed as described previously [32]. In short, equal amounts of protein (25$100 \mu \mathrm{g}$ ) were separated on 10\% SDS-PAGE gels and transferred to PVDF membranes (Bio-Rad Laboratories, Berkeley, CA, USA). After blocking in Odyssey blocking buffer (LI-COR Biosciences, Lincoln, AKUSA), membranes were incubated with appropriate primary antibodies (for details, see Additional file 1: Table S1) overnight in Odyssey blocking buffer at $4^{\circ} \mathrm{C}$. Primary antibodies were detected by incubation with appropriate IRDye secondary antibodies (LI-COR Biosciences) for 1 hour at RT in Odyssey blocking buffer and quantified using the Odyssey infrared imaging system (LI-COR Biosciences).

\section{Functional analysis of cells overexpressing Prx3, Trx2 and PGC-1a}

Stable cell lines transduced with Prx3, Trx2 and PGC- $1 \alpha$ containing lentiviral vector or empty pRRL vector were plated in 96-well plates (Greiner Bio-One, Frickenhausen, Germany) and grown until confluent. Cells were treated with $200 \mu \mathrm{M}$ of $\mathrm{tbH}_{2} \mathrm{O}_{2}$ for 6 hours. Hereafter, cell viability was assessed using the LIVE/DEAD Viability/ Cytotoxicity kit (Invitrogen) according to the manufacturer's protocol. Fluorescent signals were measured with the Fluostar Galaxy (BMG Labtech, Ortenberg, Germany) fluometer and the ratio between dead and live cells was calculated. Endogenous ROS production was assessed using 5-(and-6)-chloromethyl-2',7'-dichlorodihydrofluorescein di-acetate, acetyl ester (CM-H2DCFDA; Invitrogen), a probe which turns fluorescent upon oxidation. Total fluorescence was measured with the Fluostar Galaxy (BMG Labtech, Ortenberg, Germany) and corrected for live cell number.

\section{Enzyme linked immunosorbent assays (ELISA)}

Secretomes of mock and PGC1 $\alpha+$ astrocytes treated for 24 hours with or without TNF- $\alpha$ and IFN- $\gamma(5 \mathrm{ng} / \mathrm{ml}$; Peprotech, UK) were harvested and stored at $-80^{\circ} \mathrm{C}$ for further analysis. The Human IL-6 Cytoset ${ }^{\mathrm{Tm}}$ (Invitrogen) and Human CCL2 DuoSet ${ }^{\odot}$ (R\&D system, Minneapolis, MN) ELISA kits were used to determine the amount of IL-6 and CCL2 secreted by primary human astrocytes. ELISA was performed according to manufactures protocol 


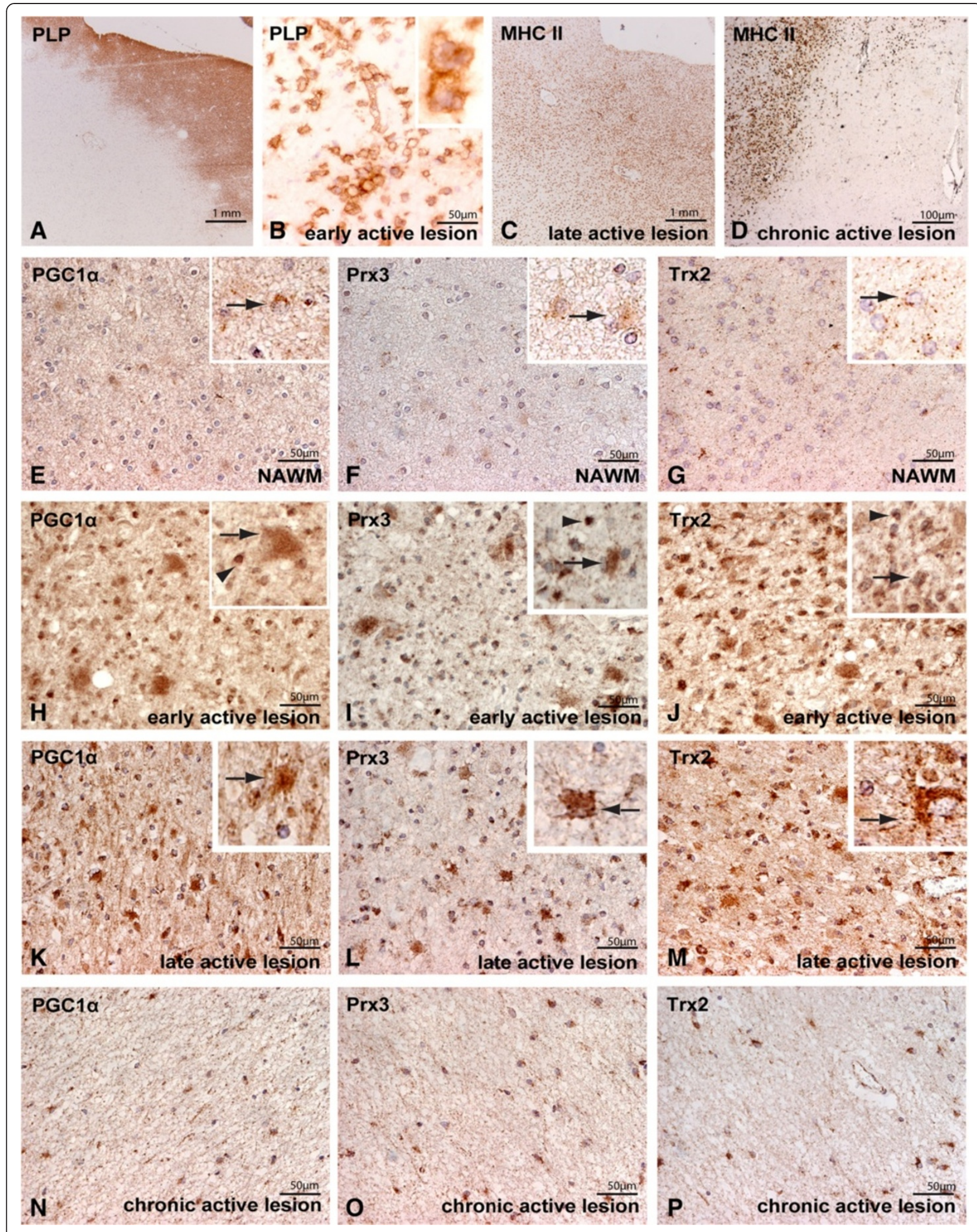

Figure 1 (See legend on next page.) 
(See figure on previous page.)

Figure 1 Increased expression of PGC-1alpha and downstream mitochondrial antioxidants in active MS lesions. MS lesions are characterized by loss of proteolipid protein (PLP; $\mathbf{A})$. In early active lesions densely packed macrophages containing myelin proteins are present (B, inset), late active lesions typically contain MHCIl positive leukocytes throughout the lesion area (C). Chronic active MS lesions are characterized by a rim of activated microglia/macrophages at the border of the lesion which are absent in the lesion center (D). Low PGC-1a, Prx3 and Trx2 immunostaining was observed in the NAWM (E-G, insets). Early active lesions showed enhanced PGC-1a, Prx3 and Trx2 immunoreactivity in astrocytes (arrow) and oligodendrocytes (arrowhead) (H-J, insets). In late active lesion expression is predominantly localized to astrocytes (arrow) (K-M, insets), which was largely lost in the inactive center of chronic active lesions (N-P).

and absorbance was analyzed at $450 \mathrm{~nm}$ with $570 \mathrm{~nm}$ wavelength correction on a spectrophotometer (Bio-Rad, Hercules, CA).

\section{Statistical analysis}

Student's t-test was applied to determine differences between PGC-1 $\alpha$ - and mock transduced astrocytes with regard to viability, ROS production and cytokine production. 2-Way ANOVA with Bonferroni post-hoc test was used to analyze the co-culture experiments and asses differences between Prx3-, Trx2- and mock-transduced astrocytes.

\section{Results}

Mitochondrial antioxidant expression in MS white matter

The early active lesion area in acute MS cases is characterized by severe demyelination (Figure 1A), massive microglial activation and the presence of densely packed macrophages containing myelin degradation products (Figure 1B) [33]. Late active MS lesions contain abundant leukocyte infiltrates throughout the lesion area, but lack PLP-positive macrophages (Figure 1C). Chronic active lesions are characterized by a rim of MHC class IIpositive activated microglia and a demyelinated center devoid of inflammatory cells (Figure 1D).

PGC-1 $\alpha$, Prx3 and Trx2 were weakly expressed in astrocytes in normal appearing white matter (NAWM) (Figure 1E-G) and control white matter and no marked differences were observed comparing the intensity and cellular localization of PGC-1 $\alpha$, Prx3 and Trx2 immunostainings in NAWM with control white matter (data not shown). The expression of PGC-1 $\alpha$, Prx3 and Trx2 was strikingly upregulated in early active lesions compared to surrounding NAWM and localized to astrocytes (arrows) and oligodendrocytes (arrowheads) (Figure 1H-J). PGC-1 $\alpha$, Prx3 and Trx2 immunoreactivity was also consistently increased in late active lesions compared to NAWM, albeit less pronounced compared to early active lesions (Figure $1 \mathrm{~K}-\mathrm{M}$ ). In late active lesions PGC-1 $\alpha$, Prx3 and Trx2 predominantly localized to cells with the morphological appearance of reactive astrocytes. In contrast to early active lesions, we did not find abundant oligodendrocyte expression of PGC- $1 \alpha, \operatorname{Prx} 3$ and Trx 2 in late active lesions. Expression levels of PGC-1 $\alpha$, Prx3 and Trx2 in the inactive center of chronic active lesions were similar as observed in the NAWM (Figure 1N-P). Immunofluorescent triple stainings with glial fibrillary acidic protein (GFAP, astrocyte marker) and carbonic anhydrase II (CAII, oligodendrocyte marker) confirmed the cellular localization in astrocytes and oligodendrocytes (arrowhead) in early active lesions (Figure 2A-C). In late active MS lesions, PGC-1 $\alpha$ (Figure 2D), Prx3 (Figure 2E) and Trx2 (Figure 2F) predominantly localized to astrocytes and to a much lesser extent to oligodendrocytes (2G-I). Mitochondrial antioxidant enzymes are weakly expressed in axons in active MS lesions (Additional file 3: Figure S1) and no apparent changes were observed between patients and controls (data not shown). Co-localization studies with the mitochondrial protein porin indicate that outside the nucleus, PGC- $1 \alpha$ is expressed in mitochondria as described previously (Additional file 3: Figure S1) [34].

Taken together, the expression of PGC-1 $\alpha$ and the mitochondrial antioxidant enzymes Prx3 and Trx2 is strongly increased in astrocytes in active MS lesions. In contrast, in the inactive center of chronic active demyelinated lesions the expression of PGC- $1 \alpha$, Prx3 and Trx 2 returned to levels similar to the NAWM.

\section{Regulation and protective effect of astrocytic PGC-1a under oxidative stress}

To determine whether oxidative stress underlies the observed increase in astrocytic PGC- $1 \alpha$ and mitochondrial antioxidant expression, human astrocytes were exposed to $50 \mu \mathrm{M}$ tert-butyl hydrogen peroxide $\left(\mathrm{tbH}_{2} \mathrm{O}_{2}\right)$ for 24 hours. Exposure to ROS significantly increased gene expression of Prx3, Trx 2 and PGC- $1 \alpha$ in human astrocytes (Figure 3A). Next, human astrocytes were stably transduced with PGC-1 $\alpha$ containing lentivirus (PGC- $1 \alpha^{+}$ astrocytes) thereby increasing expression of PGC- $1 \alpha$ and its downstream targets Prx3 and Trx2 (Figure 3B). Overexpression of PGC-1 $\alpha$ markedly increased the resistance of astrocytes against an oxidative attack (Figure $3 \mathrm{C}$ ) and completely abolished oxidative stress-induced intracellular ROS production (Figure 3D). In order to assess the effect of PGC-1 $\alpha$ upregulation in astrocytes on surrounding cells, $\mathrm{GFP}^{+}$neuronal cells were co-cultured with mock-transduced or PGC- $1 \alpha^{+}$astrocytes and subsequently stimulated with $200 \mu \mathrm{M}$ tbH $\mathrm{H}_{2} \mathrm{O}_{2}$ for 6 hours. Neuronal cell death was significantly reduced when cocultured with PGC-1 $\alpha^{+}$astrocytes compared to mock 

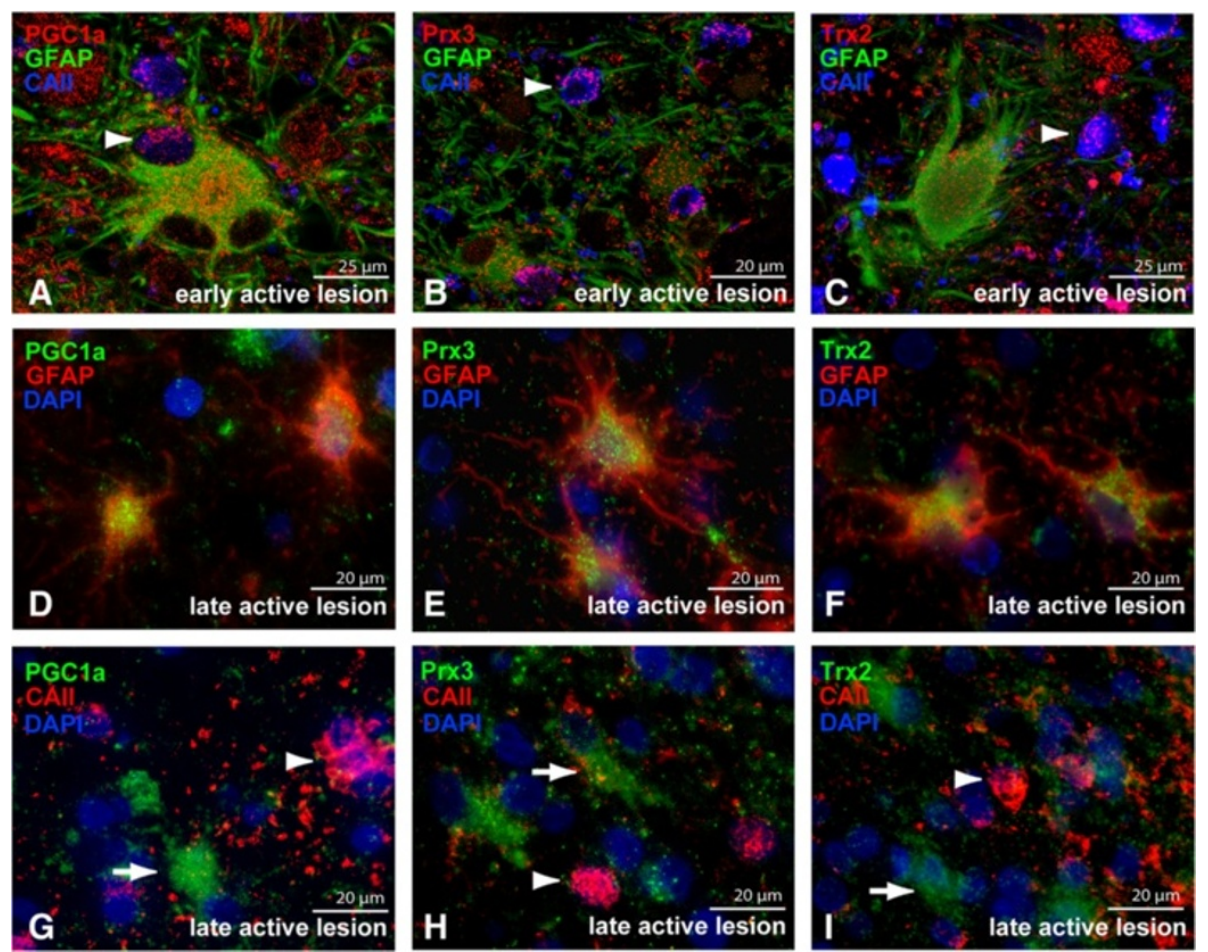

Figure 2 PGC-1alpha, Prx3 and Trx2 are mainly expressed in astrocytes. Triple immunofluorescent staining shows colocalization of PGC-1a (A, red), Prx3 (B, red), Trx2 (C, red) with GFAP-positive astrocytes (green) and CAll-positive oligodendrocytes (blue) in early active lesions. In late active lesions GFAP (red) positive cells colocalize with PGC-1a (D), Prx3 (E) and Trx2 (F). CAll positive oligodendrocytes (red, arrowheads) did not colocalize with PGC-1a (G), Prx3 (H) and Trx2 (I) in late active lesions, whereas astrocyte like cells could be clearly distinguished (arrow).

transduced astrocytes (Figure 3E). Importantly, the observed neuroprotective effect of PGC- $1 \alpha^{+}$astrocytes was not due to decreased astrocytic cell death in the PGC- $1 \alpha^{+}$ astrocytes compared to mock astrocytes as $\mathrm{GFP}^{+}$astrocytes co-cultured with $\mathrm{GFP}^{-}$neuroblastoma cells showed virtually no cell death (Figure 3E).

As shown in Figure 3B, PGC-1 $\alpha$ overexpression in astrocytes increased expression of Prx3 and Trx2, which likely contributes to the protective effect of PGC- $1 \alpha$ against oxidative stress. Primary human astrocytes were only limited available, therefore we used U373 astrocytoma cells to assess whether Prx 3 and Trx 2 overexpression resulted in increased resistance against oxidative stress. Importantly, overexpression of PGC- $1 \alpha$ in U373 cells showed similar protective effects as the PGC- $1 \alpha^{+}$ astrocytes (Additional file 4: Figure S2). Overexpression of Prx3 and Trx2 in U373 astrocyte-like cells reduced ROS production and increased viability of astrocytes and surrounding neurons upon treatment with $\mathrm{tbH}_{2} \mathrm{O}_{2}$ (Additional file 4: Figure S2). Taken together, our data indicate that ROS induce upregulation of PGC- $1 \alpha$ and downstream mitochondrial antioxidants, which in turn protects astrocytes and surrounding cells against ROSmediated cell death.
PGC $-1 \mathrm{a}^{+}$astrocytes have a reduced inflammatory profile Reactive astrocytes in MS are known to produce high levels of the pro-inflammatory factors IL-6 and CCL2, which stimulate astrogliosis, increase vascular activation and enhance migration of leukocytes into the brain [35-37]. Previous studies have shown that increased PGC- $1 \alpha$ expression can reduce the production of IL- 6 and CCL2 in skeletal muscle cells [38,39]. This prompted us to investigate the role of PGC-1 $\alpha$ on the expression of IL-6 and CCL2 in human astrocytes.

TNF- $\alpha$ and IFN- $\gamma$ are present in high concentrations in inflammatory MS lesions and treatment of astrocytes with TNF- $\alpha$ and IFN- $\gamma$ is a useful tool to create reactive astrocytes in vitro $[7,40,41]$. Interestingly, our results show that PGC- $1 \alpha^{+}$astrocytes express the pro-inflammatory genes IL- 6 and CCL2 at lower levels under basal conditions and upon stimulation with TNF- $\alpha / \mathrm{IFN}-\gamma$ compared to mock transduced astrocytes (Figure 4A-B). Secretion of IL- 6 and CCL2 was also reduced in PGC- $1 \alpha^{+}$astrocytes (Figure 4C-D). Next, we investigated whether PGC-1 $\alpha$ overexpression decreased cytokine-induced ROS production. Notably, TNF- $\alpha /$ IFN- $\gamma$-mediated ROS production was significantly reduced in $\mathrm{PGC}-1 \alpha^{+}$astrocytes compared to mock transduced astrocytes (Figure 4E). Our findings 


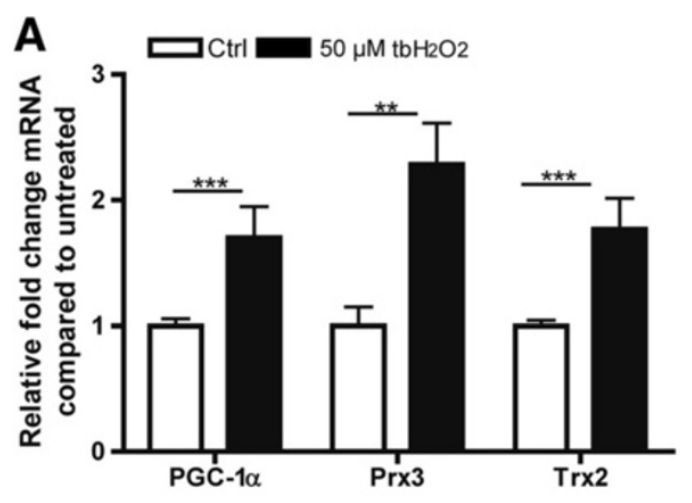

B

Mock PGC-1a
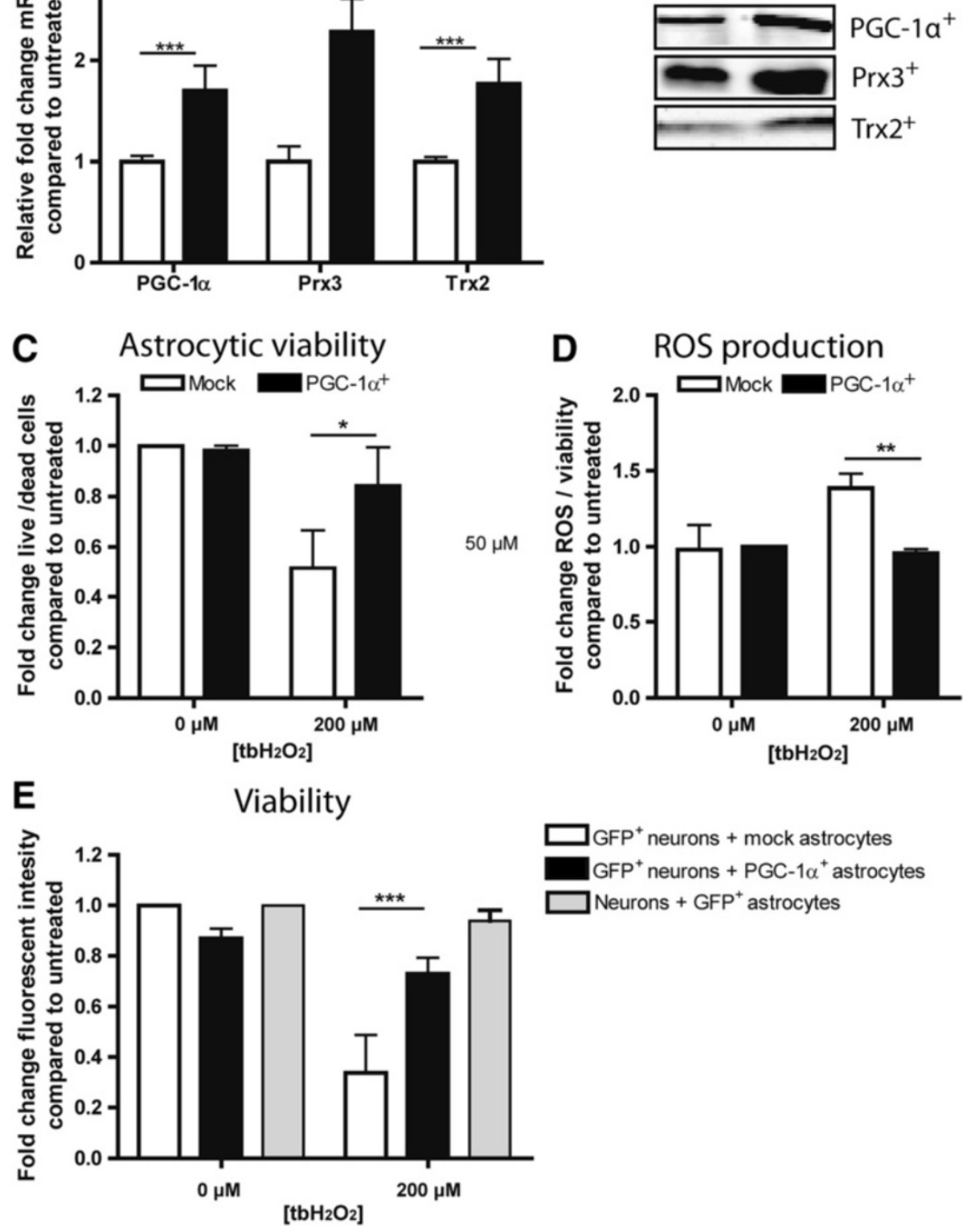

Figure 3 Regulation and protective effects of astrocytic PGC-1 alpha. Treatment of human astrocytes with $\mathrm{tbH}_{2} \mathrm{O}_{2}$ increased mRNA expression levels of PGC-1a, Prx3 and Trx2 (A). Western blot analysis illustrates that lentiviral overexpression of PGC-1a increases PGC-1a, Prx3 and Trx2 expression (B). PGC-1 $\mathrm{a}^{+}$astrocytes were more resistant to $\mathrm{tbH}_{2} \mathrm{O}_{2}$ induced cell death (C) and produced less $\mathrm{ROS}$ compared to mock-transduced astrocytes (D). SHSY5Y cells were better protected against $\mathrm{tbH}_{2} \mathrm{O}_{2}$ induced cell death when co-cultured with PGC-1 $\mathrm{a}^{+}$overexpressing astrocytes compared to mocktransduced astrocytes (E). GFP' astrocytes co-cultured with SHSY5Y cells did not show reduced viability after $\mathrm{tbH}_{2} \mathrm{O}_{2}$ treatment (E). ${ }^{*} \mathrm{P}<0.05$, ${ }^{* * P}<0.01$, ${ }^{* * *} \mathrm{P}<0.001$ as determined by students T-test for figure $\mathbf{A}, \mathbf{C}, \mathbf{D}$ and with two-way ANOVA with post-hoc Bonferroni correction for Figure $\mathbf{E}$.

indicate that PGC- $1 \alpha$, besides controlling mitochondrial redox metabolism, exerts a profound effect on the inflammatory profile of astrocytes.

\section{Discussion}

In the present study we show that the expression of the transcription co-factor proliferator-activated receptor gamma coactivator 1-alpha (PGC-1 $\alpha)$ and downstream mitochondrial antioxidant enzymes peroxiredoxin-3 (Prx3) and thioredoxin-2 (Trx2) is markedly increased in astrocytes in active multiple sclerosis (MS) lesions. Our in vitro data provide evidence that overexpression of PGC- $1 \alpha$ protects human astrocytes against oxidative stress and reduces intracellular ROS production. Moreover, co-culture 

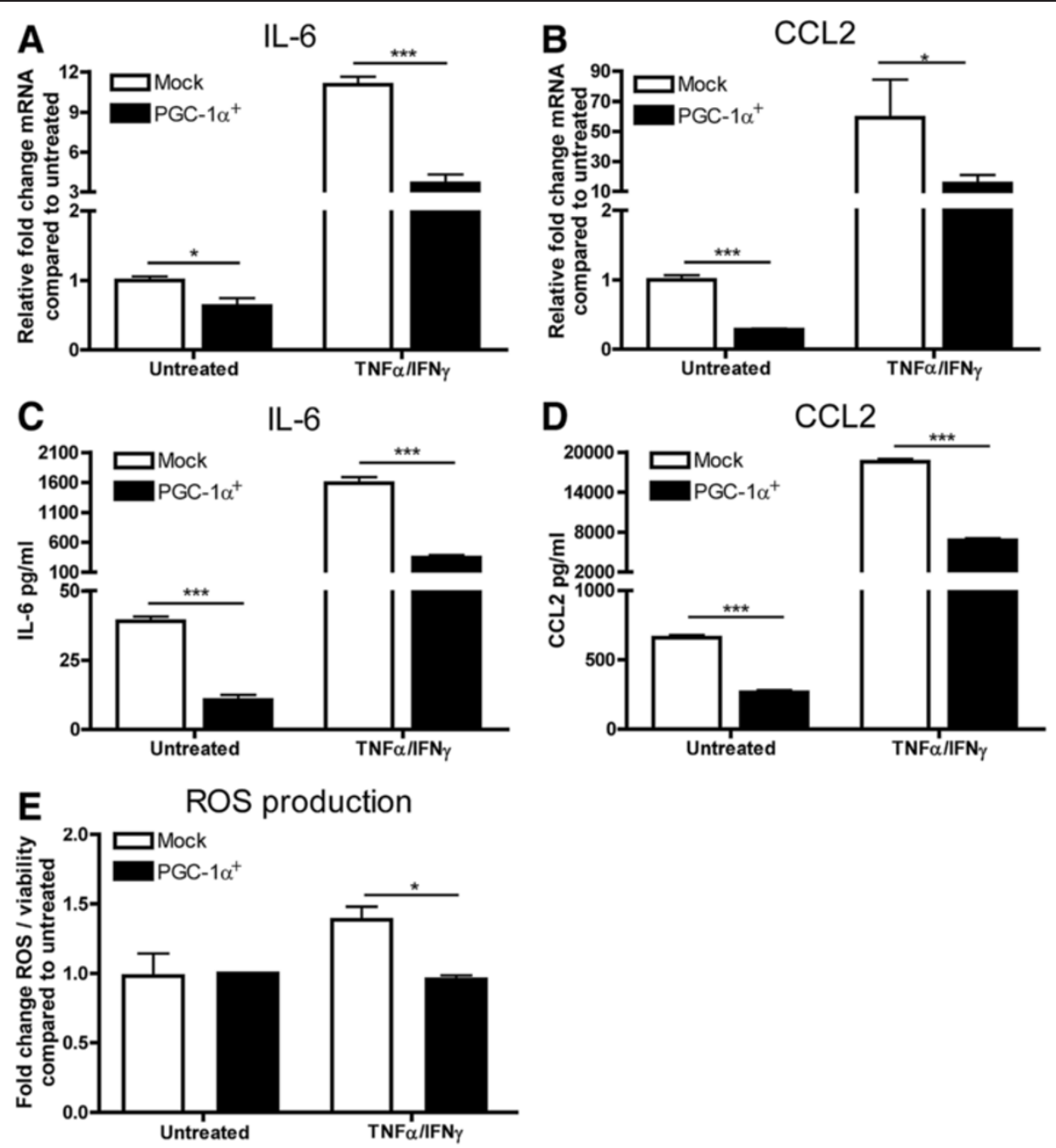

Figure 4 Inflammatory profile of PGC-1alpha overexpressing astrocytes. PGC-1 a astrocytes expressed less IL-6 (A) and CCL2 (B) mRNA under normal conditions and after $24 \mathrm{hr}$ treatment with TNFa/IFNy compared to mock-transduced astrocytes. Secretion of IL-6 (C) and CCL2 (D) by astrocytes as measured by ELISA is reduced in PGC-1 a ${ }^{+}$astrocytes. TNFa/IFNy increased ROS production in mock-transduced astrocytes but not in PGC-1a expressing astrocytes (E). ${ }^{*} \mathrm{P}<0.05$, ${ }^{*} \mathrm{P}<0.01,{ }^{* *} \mathrm{P}<0.001$ as determined by students T-test.

experiments indicate that increased expression of PGC-1 $\alpha$ in astrocytes protects neurons from ROS-induced cell death. Finally, we demonstrate that PGC-1 $\alpha$ overexpression reduces the production of astrocyte-derived inflammatory molecules.

ROS unambiguously play a cardinal role in MS pathology as recent studies demonstrate a clear association between inflammation-derived ROS, mitochondrial (dys) function and neurodegeneration [12]. Since little is known about the distribution and functional role of mitochondrial enzymes, we set out to investigate the expression of PGC1- $\alpha$ and its downstream targets Prx3 and Trx2 in a large selection of white matter MS lesions. In early active MS lesions, which represent the initial phase of MS lesions, we found a striking increase in the expression of PGC1- $\alpha$, Prx3 and Trx2 in both astrocytes and oligodendrocytes compared to NAWM and control tissue [42]. Our in vitro experiments demonstrated that astrocytes strongly upregulate PGC1- $\alpha$ and mitochondrial antioxidants upon exposure to ROS, which is in line with previous studies describing ROS-induced PGC1- $\alpha$ expression in mouse muscle and embryonic mesenchymal stem cells $[43,44]$. This likely represents a protective response to the local oxidative milieu. In fact, we show that overexpression of PGC- $1 \alpha$ or mitochondrial antioxidants protects astrocytes from ROS-induced cell death, which corroborates previous studies using different cell types and experimental animal models [21,45-47]. In late active MS lesions, enhanced PGC1- $\alpha$, Prx3 and Trx2 immunoreactivity was mainly observed in astrocytes, not oligodendrocytes. This finding suggests that surviving oligodendrocytes may lose their ability to express adequate levels of mitochondrial antioxidants in time, making them more vulnerable to ROS-induced cell 
death. Notably, oligodendrocyte loss is a key feature of inflammatory MS lesions, whereas astrocytes generally survive. Our findings are in line with previous data from our group in which we showed that astrocytes effectively induce cytoplasmic antioxidant levels in late active MS lesions [10]. Besides oligodendrocytes, axons represent the main victims of the oxidative attack in inflammatory lesions [25]. Remarkably, similar to previous observations for cytoplasmic antioxidants, we found no evident increase in mitochondrial antioxidant defence mechanisms in axons in any stage of MS pathology [10]. A likely explanation is that the distance between the cell body, where PGC- $1 \alpha$ induces expression of mitochondrial antioxidants, and the affected axon is too large for a timely and efficient antioxidative response. Moreover, we previously showed that PGC- $1 \alpha, \operatorname{Prx} 3$ and Trx 2 are decreased in cortical neurons of MS patients, suggesting that reduced PGC- $1 \alpha$ in cortical neuronal cell bodies might contribute to the lack of mitochondrial antioxidant induction in demyelinated axons [22]. Taken together, the relative inability of axons and oligodendrocytes to increase their mitochondrial antioxidative capacity in response to an oxidative attack likely contributes to the extensive oxidative damage of axons and oligodendrocytes and subsequent cell death in MS lesions.

Loss of PGC- $1 \alpha$ in cultured neurons induces intracellular ROS production and the susceptibility to ROSinduced cell death [22]. In this study we show for the first time that enhanced astrocytic expression of PGC- $1 \alpha$ and mitochondrial antioxidants is able to protect adjacent neurons from exogenous ROS in vitro. A potential explanation for the intriguing neuroprotective effect is that astrocytes can shuttle antioxidants to neurons, thereby enhancing neuronal antioxidant capacity. This has been shown for glutathione, but it remains unknown whether Prx3 and Trx2 are also secreted by astrocytes $[48,49]$. Interestingly, PGC- $1 \alpha$ can also stimulate the production of enzymes involved in glutathione biosynthesis

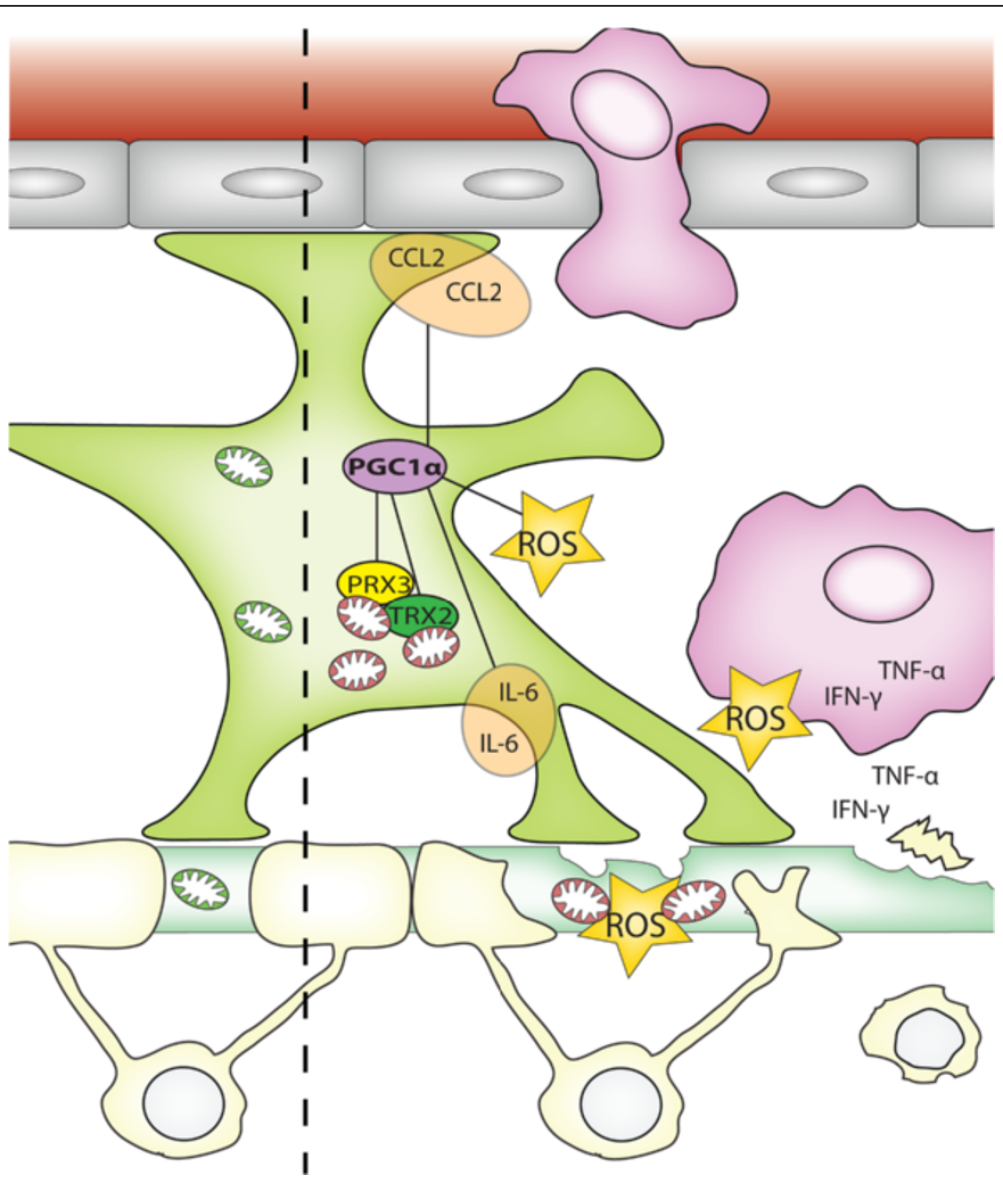

Figure 5 Graphical abstract. Macrophages are attracted by CCL2 and infiltrate the brain, phagocytose myelin and produce high amounts of ROS and TNF-a and IFN- . This will lead to mitochondrial stress, resulting in more mitochondrial ROS production contributing to axonal degeneration. Increased amounts of ROS induce astrocytic PGC-1a, which increases mitochondrial antioxidant capacity via upregulation of Prx3 and Trx2. Increased expression of PGC-1a, Prx3 or Trx2 protects astrocytes and surrounding neurons not only from mitochondrial stress but also against exogenous ROS. Interestingly, PGC-1a can reduce CCL2 and IL-6 production and TNF-a/IFN- $-\gamma$ induced ROS production, thereby dampening inflammation. Thus increased astrocytic PGC-1alpha can reduce ROS and inflammation in MS lesions which protects surrounding axons and neurons. 
[50]. However, we demonstrate that overexpression of astroglial Prx3 or Trx2 alone is sufficient to protect surrounding neurons against an oxidative insult. The precise mechanism how enhanced levels of astroglial PGC-1 $\alpha$ and downstream mitochondrial antioxidant enzymes protect neighbouring cells warrants future research, but astrocytes may scavenge extracellular ROS and by preserving their mitochondrial function during oxidative stress, astrocytes remain able to provide support to adjacent neurons. Nonetheless, neuro-axonal damage is profound in (early) active MS lesions indicating that the increase in astroglial mitochondrial antioxidants is not sufficient to protect all neighbouring axonal structures and cells [25].

PGC- $1 \alpha$ regulates the transcription of a broad array of genes and is a key player in mitochondrial biogenesis, consequently it is conceivable that the protective effects of enhanced PGC- $1 \alpha$ levels extend beyond increased mitochondrial antioxidant production [24]. Since PGC-1 $\alpha$ has such widespread effects and evidence for an intricate relationship between cellular metabolism and inflammation is mounting, we were interested whether astroglial PGC- $1 \alpha$ was able to influence the production of inflammatory mediators $[51,52]$. In inflammatory MS lesions, reactive astrocytes are known to produce high amounts of IL-6 and CCL2 thereby contributing to the ongoing inflammation $[35,36]$. Interestingly, PGC- $1 \alpha$ overexpression strongly reduced the production of astrocytic IL-6, CCL2 and ROS upon treatment with key pro-inflammatory mediators. The anti-inflammatory effects of PGC- $1 \alpha$ could be mediated by PGC-1 $\alpha$-induced PPAR signalling which is known to reduce IL- 6 and CCL 2 production by astrocytes, however future studies are needed to elucidate the antiinflammatory properties of PGC-1 $\alpha$ [53].

This study provides novel insights in the protective properties of reactive astrocytes. We previously showed that reactive astrocytes produce both pro- and antiinflammatory mediators, but they are vital for tissue repair since ablation of astrocyte activation enhances CNS damage in various experimental models [6,7,54-56]. Thus, therapies aimed at augmenting the production and activity of mitochondrial antioxidants in neurons, but also in astrocytes, represent an interesting strategy to restore mitochondrial function and combat neurodegeneration. Activation of the PGC- $1 \alpha$ pathway is of particular interest since this will not only boost the (mitochondrial) antioxidants machinery, but, in addition, also promotes expression of a variety of proteins involved in energy metabolism and suppresses inflammation [26]. Several studies have shown that resveratrol and progesterone, both known to activate PGC- $1 \alpha$, are neuroprotective and reduce clinical symptoms in experimental autoimmune encephalitis (EAE) [57-59]. Interestingly, overexpression of sirtuin 1 (Sirt1), a direct activator of PGC-1 $\alpha$, is also neuroprotective and reduces clinical symptoms in EAE [60].

\section{Conclusion}

In conclusion, we have shown increased PGC- $1 \alpha$ and downstream mitochondrial antioxidant enzyme expression in astrocytes in inflammatory MS lesions. Overexpression of PGC- $1 \alpha$ in primary human astrocytes attenuates intracellular ROS production and protects astrocytes as well as surrounding cells from ROS-mediated cell death. Moreover, we provide evidence that PGC- $1 \alpha$ limits the production of astrocyte-derived inflammatory molecules (Figure 5). Hence, activation of the PGC- $1 \alpha$ pathway represents an attractive approach to limit both inflammation and oxidative stress, two key features of MS pathogenesis.

\section{Additional files}

Additional file 1: Table S1. Antibody details.

Additional file 2: Table S2. Primer sequences.

Additional file 3: Figure S1. Prx3 (A, C, green) and Trx2 (B,D, green) staining was found to colocalize with both non-phosphorylated- (SMI32; in red) and phosphorylated axons (SMI31, in red). PGC-1a is localized in both mitochondria (porin, red) and nuclei (DAPI, blue) (N).

Additional file 4: Figure S2. Western blot analysis shows that U373 astrocyte-like cells treated with Prx3 and Trx2 containing lentiviral constructs have increased Prx3 and Trx2 protein expression compared to mock transduced U373 cells (A). PGC- $1 a^{+}$U373 have increased protein expression of PGC-1a, Prx3 and Trx2 (B). Live/dead viability assay revealed reduced vulnerability of astrocyte-like cells overexpressing Prx3, Trx2 or PGC-1a to $\mathrm{tbH}_{2} \mathrm{O}_{2}$ treatment $(\mathbf{C}, \mathbf{D})$. ROS production was increased in mock-transduced U373s compared to PrX3 $3^{+}$, Trx2 $2^{+}$or PGC $-1 a^{+}$U373 cells $(\mathbf{E}, \mathrm{F})$. GFP ${ }^{+} \mathrm{SH} 5 \mathrm{YSY}$ cells were better protected against $\mathrm{tbH}_{2} \mathrm{O}_{2}$ when cultured together with ${\mathrm{Pr} \times 3^{+}}^{+}, \mathrm{Tr} \times 2^{+}$or $\mathrm{PGC}-1 \mathrm{a}^{+}$astrocytes compared to mock-transduced astrocytes $(\mathbf{G}, \mathbf{H})$. U373 cells treated with the same concentrations of $\mathrm{tbH}_{2} \mathrm{O}_{2}$ as the neuronal cultures showed no difference in viability between the different cell lines $(\mathbf{I}, \mathbf{J})$. Significance was compared to Mock cells. ${ }^{* P}<0.05,{ }^{* * P}<0.01,{ }^{* * * P}<0.001$ as determined by two-way ANOVA with post-hoc Bonferroni correction.

\section{Competing interests}

The authors declare that they have no competing interests.

\section{Acknowledgements}

This work was supported by grants from the Dutch MS Research Foundation (PN 09-358, AR and HEdeV, grant 08-642, JVH 09-686), which had no role in study design, data collection and analysis, decision to publish, or preparation of the manuscript. We would like to acknowledge Professor Jones (Emory University, Atlanta, GA, USA) and Professor Strömstedt (Department of Pharmaceutical Biosciences, University of Oslo, Norway) for kindly providing us with the Trx2 and PGC-1a plasmids.

\section{Author details}

'Department of Pathology, MS Center Amsterdam, VU University Medical Center, Amsterdam, The Netherlands. ${ }^{2}$ Department of Molecular Cell Biology and Immunology, Neuroscience Campus Amsterdam, VU University Medical Center, Amsterdam, The Netherlands. ${ }^{3}$ Department of Neuroimmunology, Center for Brain Research, Medical University of Vienna, Wien, Austria. ${ }^{4}$ Institute of Clinical Neuroimmunology, Ludwig-Maximilians University Munich, Munich, Germany.

Received: 26 November 2014 Accepted: 27 November 2014 Published online: 10 December 2014

\section{References}

1. Compston A (2005) McAlpine's Multiple Sclerosis

2. Frohman EM, Racke MK, Raine CS (2006) Multiple Sclerosis-the Plaque and Its Pathogenesis. N Engl J Med 354:942-955 
3. Fischer MT, Sharma R, Lim JL, Haider L, Frischer JM, Drexhage J, Mahad D, Bradl M, van Horssen J, Lassmann H (2012) NADPH Oxidase expression in active multiple sclerosis lesions in relation to oxidative tissue damage and mitochondrial injury. Brain 135:886-899

4. Brosnan CF, Raine CS (2013) The astrocyte in multiple sclerosis revisited. Glia 61:453-465

5. Miljkovi-ç D, Timotijevi-ç G, Stojkovi-ç MM (2011) Astrocytes in the tempest of multiple sclerosis. FEBS Lett 585:3781-3788

6. Doorn R, Nijland P, Dekker N, Witte M, Lopes-Pinheiro M, van het Hof B, Kooij G, Reijerkerk A, Dijkstra C, Valk P, Horssen J, Vries H (2012) Fingolimod attenuates ceramide-induced BloodGÇôbrain barrier dysfunction in multiple sclerosis by targeting reactive astrocytes. Acta Neuropathol 124:397-410

7. Mizee M, Nijland P, van der Pol S, Drexhage J, van het Hof B, Mebius R, van der Valk P, van Horssen J, Reijerkerk A, de Vries H (2014) Astrocyte-derived retinoic acid: a novel regulator of BloodGÇôbrain barrier function in multiple sclerosis. Acta Neuropathol 128(5):691-703

8. Sofroniew M, Vinters H (2010) Astrocytes: biology and pathology. Acta Neuropathol 119:7-35

9. Kostianovsky AM, Maier LM, Anderson RC, Bruce JN, Anderson DE (2008) Astrocytic regulation of human monocytic/microglial activation. J Immunol 181:5425-5432

10. Van Horssen J, Schreibelt G, Drexhage J, Hazes T, Dijkstra CD, van der Valk P, De Vries HE (2008) Severe oxidative damage in multiple sclerosis lesions coincides with enhanced antioxidant enzyme expression. Free Radic Biol Med 45:1729-1737

11. Liddell JR, Robinson SR, Dringen R, Bishop GM (2010) Astrocytes retain their antioxidant capacity into advanced old age. Glia 58:1500-1509

12. Witte ME, Mahad DJ, Lassmann H, van Horssen J (2014) Mitochondrial dysfunction contributes to neurodegeneration in multiple sclerosis. Trends Mol Med 20:179-187

13. Dutta R, McDonough J, Yin X, Peterson J, Chang A, Torres T, Gudz T, Macklin WB, Lewis DA, Fox RJ, Rudick R, Mirnics K, Trapp BD (2006) Mitochondrial dysfunction as a cause of axonal degeneration in multiple sclerosis patients. Ann Neurol 59:478-489

14. Mahad DJ, Ziabreva I, Campbell G, Lax N, White K, Hanson PS, Lassmann H, Turnbull DM (2009) Mitochondrial changes within axons in multiple sclerosis. Brain 132:1161-1174

15. Witte ME, Bo L, Rodenburg RJ, Belien JA, Musters R, Hazes T, Wintjes LT, Smeitink JA, Geurts JJ, De Vries HE, Van D, Valk P, van Horssen J (2009) Enhanced number and activity of mitochondria in multiple sclerosis lesions. J Pathol 219:193-204

16. Watabe S, Hiroi T, Yamamoto Y, Fujioka Y, Hasegawa H, Yago N, Takahashi SY (1997) SP-22 Is a thioredoxin-dependent peroxide reductase in mitochondria. Eur J Biochem 249:52-60

17. Spyrou G, Enmark E, Miranda-Vizuete A, Gustafsson J (1997) Cloning and expression of a novel mammalian thioredoxin. J Biol Chem 272:2936-2941

18. Bell KF, Hardingham GE (2011) CNS peroxiredoxins and their regulation in health and disease. Antioxid Redox Signal 14(8):1467-1477

19. Patenaude A, Murthy MR, Mirault ME (2005) Emerging Roles of thioredoxin cycle enzymes in the central nervous system. Cell Mol Life Sci 62:1063-1080

20. Hattori F, Murayama N, Noshita T, Oikawa S (2003) Mitochondrial Peroxiredoxin-3 protects hippocampal neurons from excitotoxic injury in vivo. J Neurochem 86:860-868

21. Hwang IK, Yoo KY, Kim DW, Lee CH, Choi JH, Kwon YG, Kim YM, Choi SY, Won MH (2010) Changes in the expression of mitochondrial peroxiredoxin and thioredoxin in neurons and glia and their protective effects in experimental cerebral ischemic damage. Free Radic Biol Med 48:1242-1251

22. Witte M, Nijland P, Drexhage J, Gerritsen W, Geerts D, het Hof B, Reijerkerk A, Vries H, Valk P, Horssen J (2013) Reduced expression of PGC-1alpha partly underlies mitochondrial changes and correlates with neuronal loss in multiple sclerosis cortex. Acta Neuropathol 125:231-243

23. Hock MB, Kralli A (2009) Transcriptional control of mitochondrial biogenesis and function. Annu Rev Physiol 71:177-203

24. Ventura-Clapier R, Garnier A, Veksler V (2008) Transcriptional control of mitochondrial biogenesis: the Central Role of PGC-1alpha. Cardiovasc Res 79:208-217

25. Haider L, Fischer MT, Frischer JM, Bauer J, Hoftberger R, Botond G, Esterbauer H, Binder CJ, Witztum JL, Lassmann H (2011) Oxidative damage in multiple sclerosis lesions. Brain 134:1914-1924

26. Nijland PG, Michailidou I, Witte ME, Mizee MR, van der Pol SMA, van het Hof B, Reijerkerk A, Pellerin L, van der Valk P, de Vries HE, van Horssen J (2014)
Cellular distribution of glucose and monocarboxylate transporters in human brain white matter and multiple sclerosis lesions. Glia 62:1125-1141

27. Bien CG, Vincent A, Barnett MH, Becker AJ, Blümcke I, Graus F, Jellinger KA, Reuss DE, Ribalta T, Schlegel J, Sutton I, Lassmann H, Bauer J (2012) Immunopathology of autoantibody-associated encephalitides: clues for pathogenesis. Brain 135:1622-1638

28. Zhang H, Go YM, Jones DP (2007) Mitochondrial Thioredoxin-2/Peroxiredoxin-3 System Functions in Parallel With Mitochondrial GSH System in Protection Against Oxidative Stress. Arch Biochem Biophys 465:119-126

29. Nikolic N, Rhedin M, Rustan AC, Storlien L, Thoresen GH, Stromstedt M (2012) Overexpression of PGC-1alpha increases fatty acid oxidative capacity of human skeletal muscle cells. Biochem Res Int 2012:714074

30. Garcia-Vallejo JJ, Van DW, van Het HB, Van DI, Engelse MA, Van H,V, Gringhuis SI (2006) Activation of human endothelial cells by tumor necrosis factor-alpha results in profound changes in the expression of glycosylationrelated genes. J Cell Physiol 206:203-210

31. Durrenberger $P$, Fernando F, Magliozzi R, Kashefi S, Bonnert T, Ferrer I, Seilhean D, Nait-Oumesmar B, Schmitt A, Gebicke-Haerter P, Falkai P, Grunblatt E, Palkovits M, Parchi P, Capellari S, Arzberger T, Kretzschmar H, Roncaroli F, Dexter D, Reynolds R (2012) Selection of novel reference genes for Use in the human central nervous system: a BrainNet Europe study. Acta Neuropathol 124:893-903

32. Kooi EJ, Prins M, Bajic N, Belien JA, Gerritsen WH, Van Horssen J, Aronica E, van D, Hoozemans JJ, Francis PT, Van DV, Geurts JJ (2011) Cholinergic imbalance in the multiple sclerosis hippocampus. Acta Neuropathol 122:313-322

33. Lassmann $\mathrm{H}$ (2011) Review: the architecture of inflammatory demyelinating lesions: implications for studies on pathogenesis. Neuropathol Appl Neurobiol 37:698-710

34. Aquilano K, Vigilanza P, Baldelli S, Pagliei B, Rotilio G, Ciriolo MR (2010) Peroxisome Proliferator-Activated Receptor y Co-Activator 1alpha (PGC-1alpha) and Sirtuin 1 (SIRT1) Reside in Mitochondria. J Biol Chem 285:21590-21599

35. Van Der Voorn P, Tekstra J, Beelen RHJ, Tensen CP, van der Valk P, De Groot CJA (1999) Expression of MCP-1 by reactive astrocytes in demyelinating multiple sclerosis lesions. Am J Pathol 154:45-51

36. Schonrock LM, Gawlowski G, Bruck W (2000) Interleukin-6 expression in human multiple sclerosis lesions. Neurosci Lett 294:45-48

37. Tanuma N, Sakuma H, Sasaki A, Matsumoto Y (2006) Chemokine expression by astrocytes plays a role in microglia/macrophage activation and subsequent neurodegeneration in secondary progressive multiple sclerosis. Acta Neuropathol 112:195-204

38. Handschin C, Choi CS, Chin S, Kim S, Kawamori D, Kurpad AJ, Neubauer N, Hu J, Mootha VK, Kim YB, Kulkarni RN, Shulman Gl, Spiegelman BM (2007) Abnormal Glucose Homeostasis in Skeletal MuscleGÇôspecific PGC-1 +! Knockout Mice Reveals Skeletal MuscleGÇôpancreatic + Cell Crosstalk. J Clin Invest 117:3463-3474

39. Mormeneo $E$, Jimenez-Mallebrera C, Palomer $X$, De Nigris V, Vazquez-Carrera M, Orozco A, Nascimento A, Colomer J, Lerin C, Gomez-Foix AM (2012) PGC-1alpha induces mitochondrial and myokine transcriptional programs and lipid droplet and glycogen accumulation in cultured human skeletal muscle cells. PLoS One 7:e29985

40. Bitsch A, Kuhlmann T, Da CC, Bunkowski S, Polak T, Bruck W (2000) Tumour necrosis factor alpha MRNA expression in early multiple sclerosis lesions: correlation with demyelinating activity and oligodendrocyte pathology. Glia 29:366-375

41. Becher B, Giacomini PS, Pelletier D, McCrea E, Prat A, Antel JP (1999) Interferon-gamma secretion by peripheral blood T-cell subsets in multiple sclerosis: correlation with disease phase and interferon-beta therapy. Ann Neurol 45:247-250

42. Bruck W, Porada P, Poser S, Rieckmann P, Hanefeld F, Kretzschmar HA Lassmann H (1995) Monocyte/macrophage differentiation in early multiple sclerosis lesions. Ann Neurol 38:788-796

43. Irrcher I, Ljubicic V, Hood DA (2009) Interactions between ROS and AMP kinase activity in the regulation of PGC-1alpha transcription in skeletal muscle cells. Am J Physiol Cell Physiol 296:C116-C123

44. Mungai PT, Waypa GB, Jairaman A, Prakriya M, Dokic D, Ball MK, Schumacker PT (2011) Hypoxia triggers AMPK activation through reactive oxygen species-mediated activation of calcium release-activated calcium channels. Mol Cell Biol 31:3531-3545

45. Chen L, Na R, Gu M, Salmon AB, Liu Y, Liang H, Qi W, Van Remmen H, Richardson A, Ran Q (2008) Reduction of mitochondrial H2O2 by 
overexpressing peroxiredoxin 3 improves glucose tolerance in mice. Aging Cell 7:866-878

46. Cui L, Jeong H, Borovecki F, Parkhurst CN, Tanese N, Krainc D (2006) Transcriptional repression of PGC-1alpha by mutant huntingtin leads to mitochondrial dysfunction and neurodegeneration. Cell 127:59-69

47. St-Pierre J, Drori S, Uldry M, Silvaggi JM, Rhee J, Jager S, Handschin C, Zheng K, Lin J, Yang W, Simon DK, Bachoo R, Spiegelman BM (2006) Suppression of reactive oxygen species and neurodegeneration by the PGC-1 transcriptional coactivators. Cell 127:397-408

48. Dringen R, Pfeiffer B, Hamprecht B (1999) Synthesis of the antioxidant glutathione in neurons: supply by astrocytes of CysGly as precursor for neuronal glutathione. J Neurosci 19:562-569

49. Vargas MR, Johnson DA, Sirkis DW, Messing A, Johnson JA (2008) Nrf2 activation in astrocytes protects against neurodegeneration in mouse models of familial amyotrophic lateral sclerosis. J Neurosci 28:13574-13581

50. St-Pierre J, Lin J, Krauss S, Tarr PT, Yang R, Newgard CB, Spiegelman BM (2003) Bioenergetic analysis of peroxisome proliferator-activated receptor + ! coactivators 1alpha and 1beta (PGC-1alpha and PGC-1 beta) in muscle cells. J Biol Chem 278:26597-26603

51. O'Neill LAJ, Hardie DG (2013) Metabolism of inflammation limited by AMPK and pseudo-starvation. Nature 493:346-355

52. Tornatore L, Thotakura AK, Bennett J, Moretti M, Franzoso G (2012) The nuclear factor kappa B signaling pathway: integrating metabolism with inflammation. Trends Cell Biol 22:557-566

53. Storer PD, XU J, Chavis J, Drew PD (2005) Peroxisome proliferator-activated receptor-gamma agonists inhibit the activation of microglia and astrocytes: implications for multiple sclerosis. J Neuroimmunol 161:113-122

54. Haroon F, Drogemuller K, Handel U, Brunn A, Reinhold D, Nishanth G, Mueller W, Trautwein C, Ernst M, Deckert M, Schluter D (2011) Gp130dependent astrocytic survival is critical for the control of autoimmune central nervous system inflammation. J Immunol 186:6521-6531

55. Li L, Lundkvist A, Andersson D, Wilhelmsson U, Nagai N, Pardo AC, Nodin C, Stahlberg A, Aprico K, Larsson K, Yabe T, Moons L, Fotheringham A, Davies I, Carmeliet P, Schwartz JP, Pekna M, Kubista M, Blomstrand F, Maragakis N, Nilsson M, Pekny M (2007) Protective role of reactive astrocytes in brain ischemia. J Cereb Blood Flow Metab 28:468-481

56. Faulkner JR, Herrmann JE, Woo MJ, Tansey KE, Doan NB, Sofroniew MV (2004) Reactive astrocytes protect tissue and preserve function after spinal cord injury. J Neurosci 24:2143-2155

57. Giatti S, Caruso D, Boraso M, Abbiati F, Ballarini E, Calabrese D, Pesaresi M, Rigolio R, Santos-Galindo M, Viviani B, Cavaletti G, Garcia-Segura LM, Melcangi RC (2012) Neuroprotective effects of progesterone in chronic experimental autoimmune encephalomyelitis. J Neuroendocrinol 24:851-861

58. Garay L, Deniselle MCG, Meyer M, Costa J LL, Lima A, Roig P, DeNicola AF (2009) Protective effects of progesterone administration on axonal pathology in mice with experimental autoimmune encephalomyelitis. Brain Res 1283:177-185

59. Fonseca-Kelly Z, Nassrallah M, Uribe J, Khan RS, Dine K, Dutt M, Shindler KS (2012) Resveratrol neuroprotection in a chronic mouse model of multiple sclerosis. Front Neurol 3:84

60. Nimmagadda VK, Bever CT, Vattikunta NR, Talat S, Ahmad V, Nagalla NK, Trisler D, Judge SIV, Royal W, Chandrasekaran K, Russell JW, Makar TK (2013) Overexpression of SIRT1 protein in neurons protects against experimental autoimmune encephalomyelitis through activation of multiple SIRT1 targets. J Immunol 190:4595-4607

doi:10.1186/s40478-014-0170-2

Cite this article as: Nijland et al: Astroglial PGC-1alpha increases mitochondrial antioxidant capacity and suppresses inflammation: implications for multiple sclerosis. Acta Neuropathologica Communications 2014 2:170

\section{Submit your next manuscript to BioMed Central and take full advantage of:}

- Convenient online submission

- Thorough peer review

- No space constraints or color figure charges

- Immediate publication on acceptance

- Inclusion in PubMed, CAS, Scopus and Google Scholar

- Research which is freely available for redistribution 